\title{
Congenital anterior urethral diverticulum
}

\author{
Sanjeet Kumar Singh, Ms Ansari
}

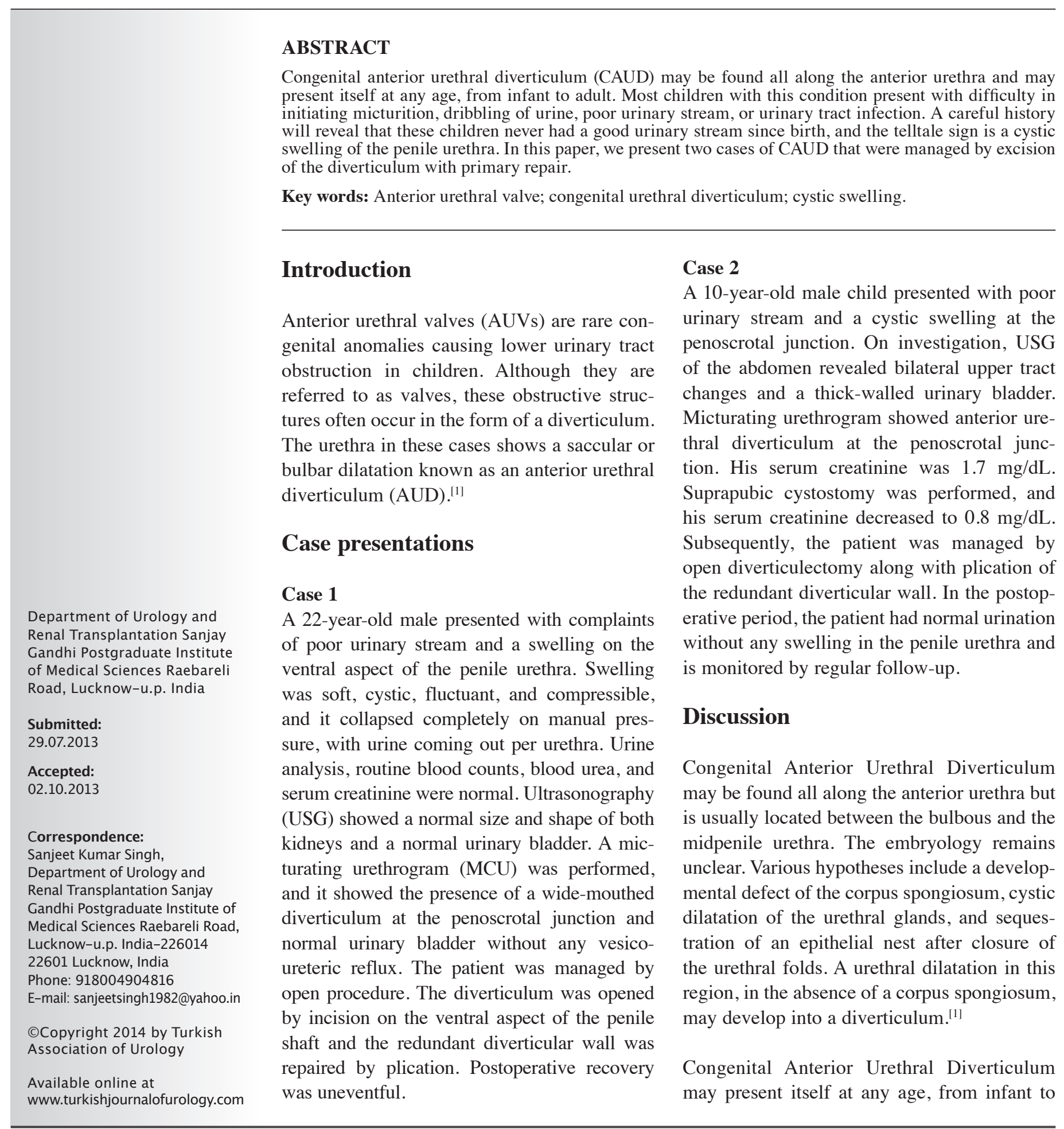



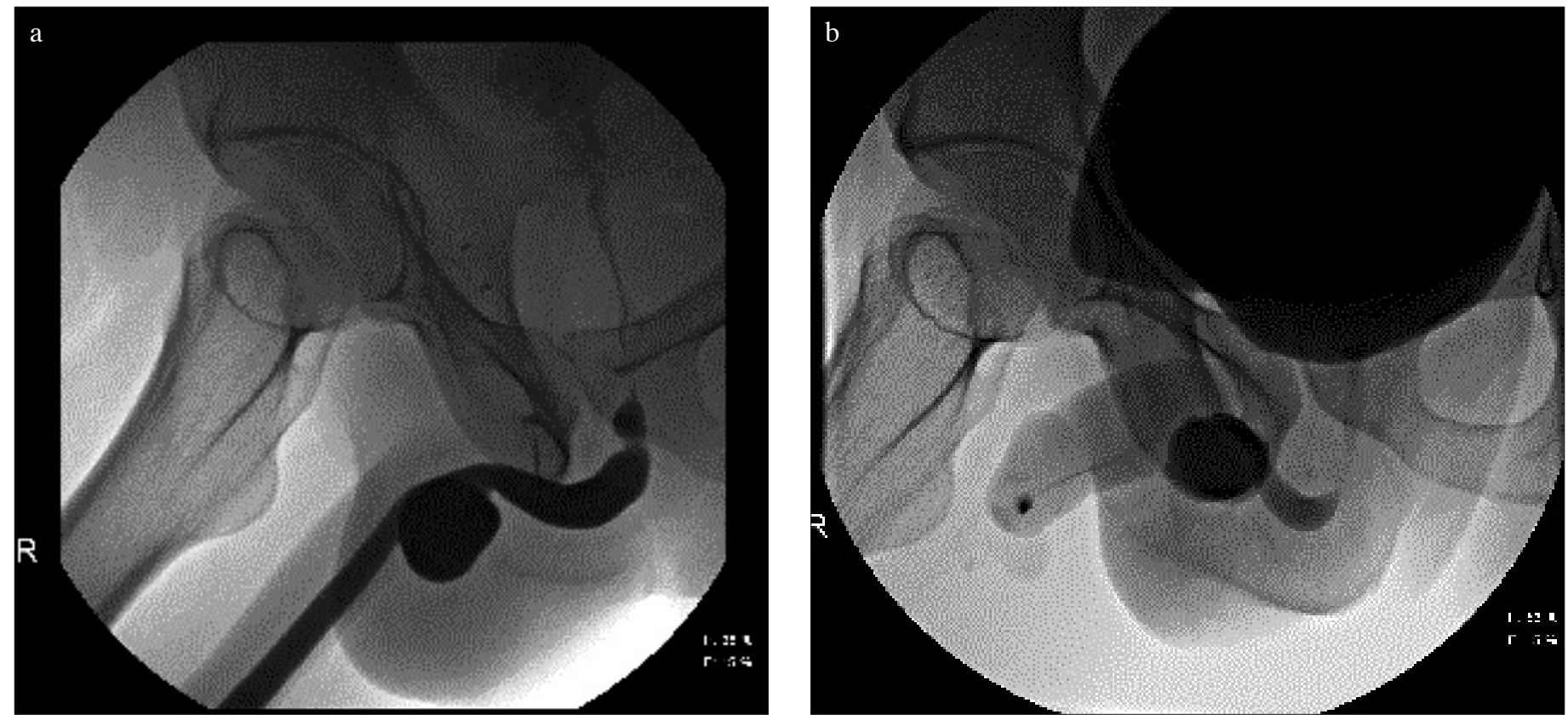

Figure 1. a, b. (a) RGU showing an anterior urethral diverticulum (b) MCU showing an anterior urethral diverticulum RGU: retrograde urethrogram; MCU: micturating urethrogram
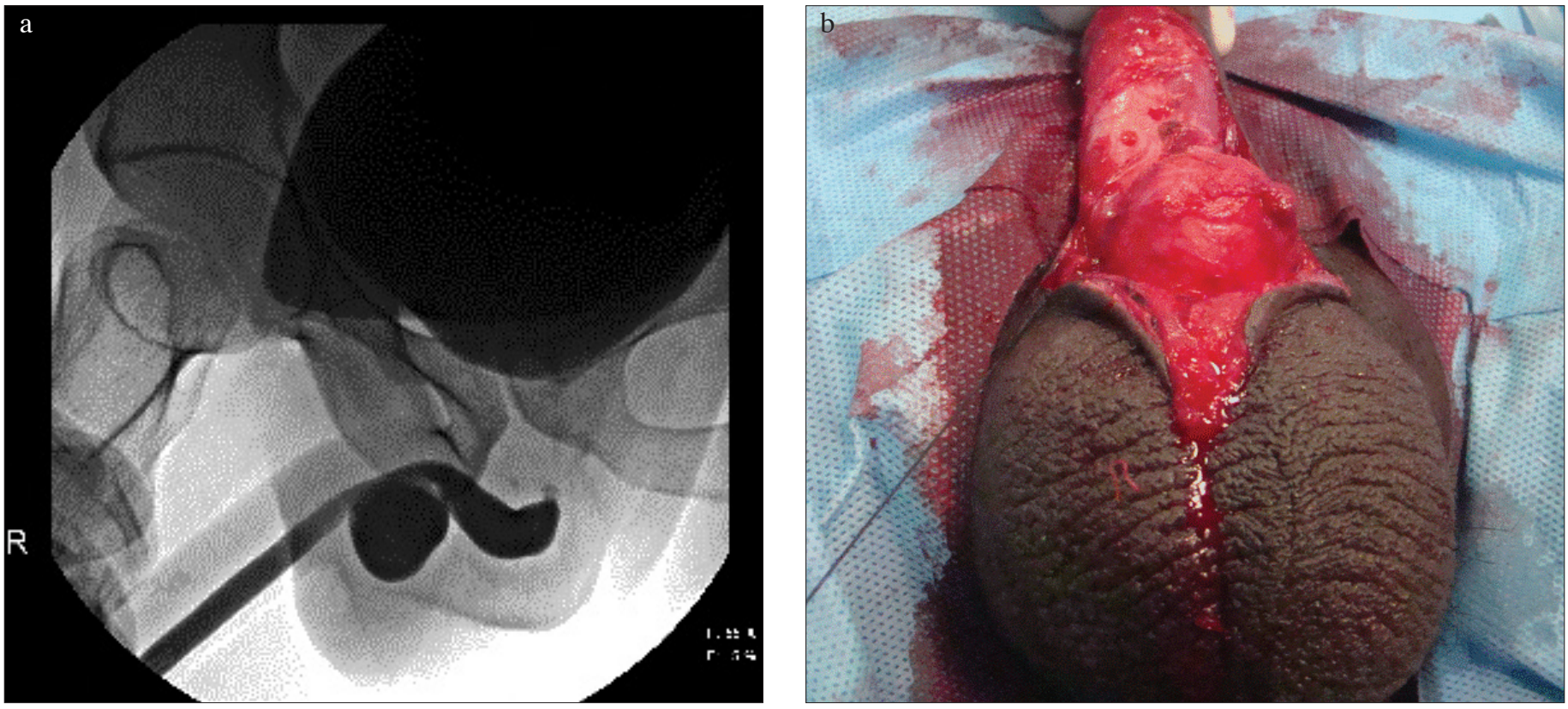

Figure 2. a, b. (a) Combined RGU with MCU showing an anterior urethral diverticulum (b) Diverticulum at the penoscrotal junction RGU: retrograde urethrogram; MCU: micturating urethrogram

adult. Most children with this condition present with difficulty in initiating micturition, dribbling of urine, poor urinary stream, or urinary tract infection. A careful history will reveal that these children never had a good urinary stream since birth, and the telltale sign is a cystic swelling at the penile urethra. ${ }^{[2]}$ On compression, urine is seen dribbling out of the external meatus, and the swelling is seen to deflate.
Diagnosis is usually made by MCUG or retrograde urethrogram. MCUG has the additional advantage of demonstrating proximal changes such as megacystis, VUR, or other associated anomalies. USG complements the contrast studies to diagnose the condition and offers the additional advantage of evaluating the upper tracts as well. Moreover, voiding USG has been found to be an alternative to the contrast studies in making a diagnosis 

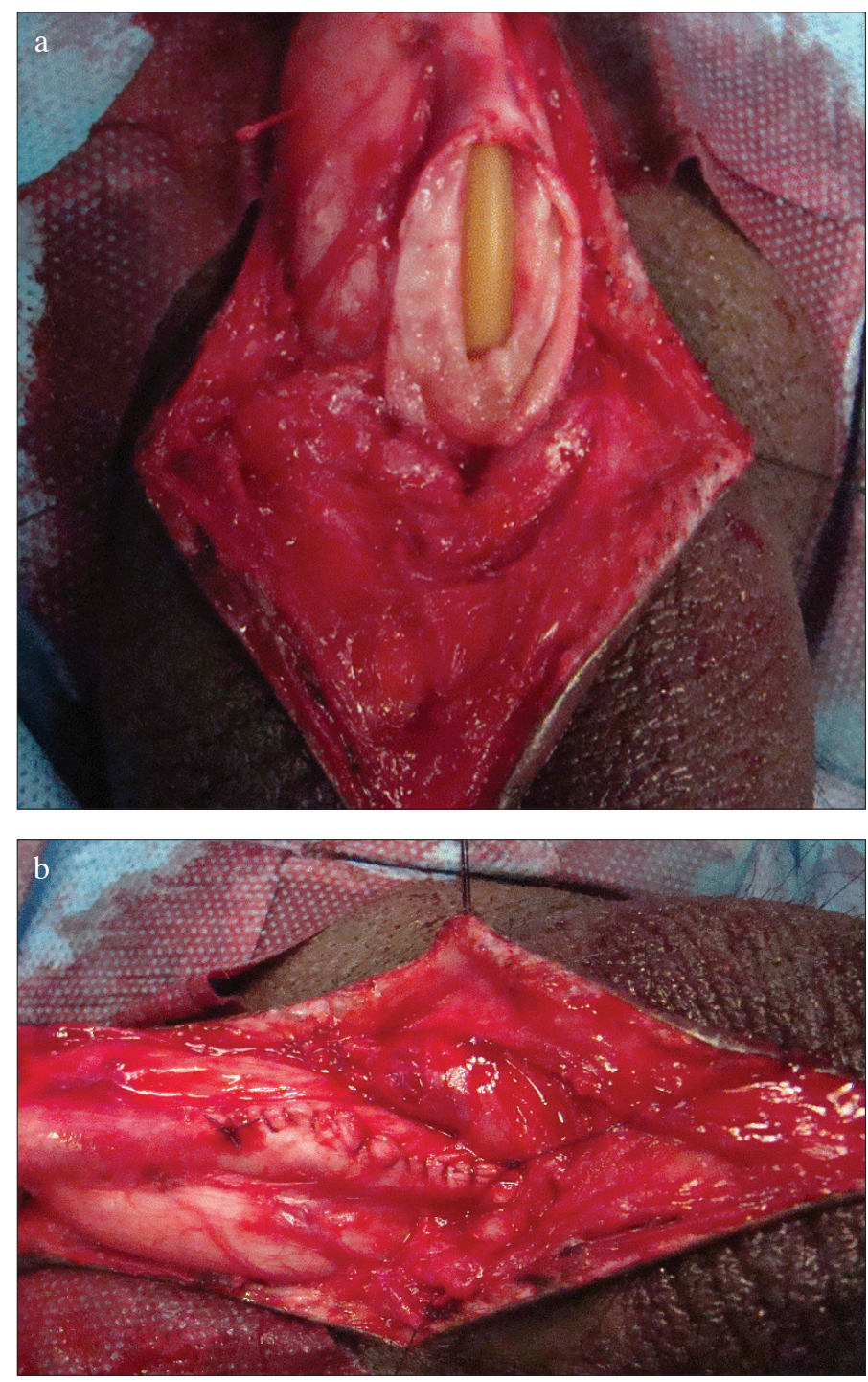

Figure 3.a,b. (a) Diverticulum after excision of the diverticular wall. (b) Diverticulum after repair

of AUD ${ }^{[3]}$ Cystourethroscopy is diagnostic as well as therapeutic. A diverticulum typically appears as an outpouching from the ventral wall of the urethra and has a proximal and distal rim. ${ }^{[4]}$

Treatment of AUD depends on the size of the diverticulum and the degree of obstruction. Transurethral resection (TUR) with a pediatric resectoscope is the treatment of choice for small, well-supported diverticula wherein the distal obstructing lip is resected ${ }^{[4]}$ However, in the large diverticula, as in our cases, open diverticulectomy and primary repair is recommended.

We have used the technique of plication of the redundant diverticular wall with good results. ${ }^{[5]}$ In situations where there are back pressure changes of upper tracts with deranged renal function, urinary diversion, either by marsupialization of the diverticulum or even suprapubic cystostomy/vesicostomy, is a safer option.${ }^{[6,7]}$ However, the prognosis depends on the status of the upper tracts, as in our second case.

Informed Consent: Written informed consent was obtained from the parents of the patients who participated in this case.

Peer-review: Externally peer-reviewed.

Author Contributions: Concept - S.K.S.; Design - S.K.S.; Supervision - M.S.A.; Materials - S.K.S.; Data Collection and/ or Processing - S.K.S.; Analysis and/or Interpretation - M.S.A.; Literature Review - S.K.S.; Writer - S.K.S.; Critical Review M.S.A.

Conflict of Interest: No conflict of interest was declared by the authors.

Financial Disclosure: The authors declared that this study has received no financial support.

\section{References}

1. Rawat J, Khan TR, Singh S, Maletha M, Kureel S. Congenital anterior urethral valves and diverticula: diagnosis and management in six cases. Afr J Paediatr Surg 2009;6:102-5.

2. Cheong WY, Cheng HK, Tan KP. Congenital anterior urethral diverticulum. Singapore Med J 1988;29:171-5.

3. Goyal M, Sharma R, Gupta DK, Sharma A, Berry M. Congenital anterior urethral diverticulum: sonographic diagnosis. J Clin Ultrasound 1996;24:543-4.

4. Heaton BW, Snow BW, Cartwright PC. Repair of urethral diverticulum by plication. Urology 1994;44:749-52.

5. Rushton HG, Parrott TS, Woodard JR, Walther M. The role of vesicostomy in the management of anterior urethral valves in neonates and infants J Urol 1987;138:107-9.

6. Zia-ul-Miraj M. Congenital anterior urethral diverticula in children. Pediatr Surg Int 1999;15:567-9.

7. Gupta DK, Srinivas M. Congenital anterior urethral diverticulum in children. Pediatr Surg Int 2000;16:565-8. 